Boak, George ORCID:

https://orcid.org/0000-0002-4489-3096 and Crabbe, Sarah ORCID: https://orcid.org/0000-0002-3172-5392 (2018) Experiences that develop leadership capabilities. Leadership \& Organization Development Journal.

Downloaded from: http://ray.yorksj.ac.uk/id/eprint/3486/

The version presented here may differ from the published version or version of record. If you intend to cite from the work you are advised to consult the publisher's version:

Research at York St John (RaY) is an institutional repository. It supports the principles of open access by making the research outputs of the University available in digital form. Copyright of the items stored in RaY reside with the authors and/or other copyright owners. Users may access full text items free of charge, and may download a copy for private study or non-commercial research. For further reuse terms, see licence terms governing individual outputs. Institutional Repository Policy Statement

\title{
RaY
}

Research at the University of York St John

For more information please contact RaY at ray@yorksj.ac.uk 


\section{Experiences that develop leadership capabilities}

\begin{tabular}{|r|l|}
\hline Journal: & Leadership \& Organization Development Journal \\
\hline Manuscript ID & LODJ-07-2018-0254.R1 \\
\hline Manuscript Type: & Research Paper \\
\hline Keywords: & $\begin{array}{l}\text { Leadership capabilities, Leadership development, Mature managers, } \\
\text { Experiential learning }\end{array}$ \\
\hline \multicolumn{2}{|l}{} \\
\hline
\end{tabular}

SCHOLARONE $^{\text {Im }}$

Manuscripts 
Experiences that develop leadership capabilities

Tables

\begin{tabular}{|l|l|l|}
\hline Experience & $\begin{array}{l}\text { Raw } \\
\text { average }\end{array}$ & $\begin{array}{l}\text { Adjusted } \\
\text { average }\end{array}$ \\
\hline Tackling a significant challenge or challenges & 4.48 & 4.51 \\
\hline Taking, or contributing to, major decisions & 4.29 & 4.36 \\
\hline Taking on new responsibilities as part of my job & 4.03 & 4.24 \\
\hline Taking on a new job (or jobs) & 3.45 & 4.24 \\
\hline Representing my team/department/organisation & 4 & 4.16 \\
\hline $\begin{array}{l}\text { Learning from other people I met through work, such as } \\
\text { clients, competitors, people from other organisations }\end{array}$ & 4.11 & 4.13 \\
\hline Acting as a mentor/coach to someone else & 3.87 & 4.04 \\
\hline Training other people in part of my/their job & 3.76 & 3.93 \\
\hline $\begin{array}{l}\text { Taking on temporary new responsibilities (eg as part of a } \\
\text { project team) }\end{array}$ & 3.55 & 3.86 \\
\hline $\begin{array}{l}\text { Working with colleagues in my organisation and learning from } \\
\text { them }\end{array}$ & 3.8 & 3.84 \\
\hline Getting informal feedback & 3.73 & 3.77 \\
\hline Supervising staff & 3.57 & 3.71 \\
\hline Seeing role model(s) & 3.54 & 3.68 \\
\hline Getting formal feedback (eg at appraisals) & 3.03 & 3.39 \\
\hline Having a mentor/coach & 2.58 & 3.33 \\
\hline Working in the same job over a period of time & 2.8 & 2.95 \\
\hline
\end{tabular}

Table 1: Experiences that have helped to develop leadership capabilities

\begin{tabular}{|l|l|}
\hline Hardships & Average \\
\hline Experiencing failures and mistakes & 2.23 \\
\hline Handling staff performance problems & 2.01 \\
\hline Having difficult relationships with colleagues, boss and others & 1.94 \\
\hline $\begin{array}{l}\text { Being turned down for contracts, promotions or other } \\
\text { opportunities }\end{array}$ & 1.45 \\
\hline Losing out in tough negotiations with colleagues, boss or others & 1.44 \\
\hline
\end{tabular}

Table 2: Hardships that helped to develop leadership capabilities 


\begin{tabular}{|l|l|}
\hline Helped with learning & Average \\
\hline Time for personal reflection & 4.69 \\
\hline Support from family/friends & 3.99 \\
\hline Advice/feedback from work colleagues & 3.95 \\
\hline Support from work colleagues & 3.88 \\
\hline Advice from family/friends & 3.58 \\
\hline Support/advice from a mentor or coach & 3.46 \\
\hline Support from line manager & 3.35 \\
\hline Advice/feedback from line manager & 3.33 \\
\hline
\end{tabular}

Table 3: Factors that helped with the learning 


\section{Experiences that develop leadership capabilities}

\section{Abstract \\ Purpose}

The research question answered by this paper is: What recent experiences - other than undertaking training and development programmes - do mature managers and professionals regard as important for their development as leaders?

\section{Design/methodology/approach}

A survey was issued to mature managers and professionals, asking them to rate the contribution of certain experiences to their recent development of leadership capabilities, and to provide qualitative data on the most important experiences.

\section{Findings}

The experience that was rated most highly in developing leadership capabilities was 'Tackling a significant challenge or challenges', followed by 'Taking, or contributing to, major decisions', and then by 'Taking on new responsibilities'. Controlled interventions such as coaching/mentoring, appraisal feedback and temporary new responsibilities were awarded relatively low ratings.

\section{Research limitations}

The sample was drawn from graduates of an executive master's degree, who are likely to have positive attitudes to self-development and to learning from experience.

\section{Practical implications}

The findings can be used to help mature leaders, and those who facilitate leadership development, to identify and use experiences that may develop leadership capabilities.

\section{Originality/value}

There are few recent studies on the kinds of experiences that are perceived to develop leadership capabilities of mature managers and professionals.

Keywords: Leadership capabilities, Leadership development, Experiential learning, Mature managers. 


\section{Experiences that develop leadership capabilities}

\section{Introduction}

The development of leadership capabilities in managers and professionals is a key area of interest and concern for organisations. Practices to facilitate leadership development in organisations include formal training and development programmes, coaching and mentoring, and supported job rotations and secondments. However, as Gold et al. (2010, p. 142) point out 'Managers often talk about informal and unplanned experiences as "explicit, powerful, relevant and realistic," and as the main source of their development.' Reviewing the nature of leadership development, Day and Thornton (2018, p. 368) note: 'Although leader/ship development programs are popular with organizations, when you ask successful senior executives about how they developed as leaders, they tend to researchers found that they claim it was through on-the-job experience.' Morgan McCall, long associated with leadership development through experiential learning, argues: 'The role played by training and other formal programs is relatively modest in comparison to other kinds of experiences.' (McCall, 2004, p. 127).

In a review of 25 years of research into leadership development, Day et al. (2014, p. 80 ) observe the importance of workplace experiences for individual development, but note:

...we lack a clear idea of the ongoing ways in which people practice to become more expert leaders. Such practice may not be intentional or mindful, which may make it more difficult to study. But this notion of ongoing practice through day-to-day leadership activities is where the crux of development really resides.

The research question for this project was:

What recent experiences - other than undertaking training and development programmes - do mature managers and professionals regard as important for their development as leaders?

Some research indicates that early life experiences may have an impact on the motivation and ability of individuals to undertake leadership responsibilities (Amit et al. , 2009; Day et al., 2014) and successful managers often attribute importance to insights gained from events early in their managerial or professional career, but this research explores recent experiences that leaders and managers perceive have helped them to develop as leaders. A practical reason for this is to inform training and development work with mature managers and professionals. And as Bennis (2003, p. 72) says about early life experiences: 'There is nothing you can do about your early life now, except to understand it. You can, however, do everything about the rest of your life.'

\section{Theoretical background}

There is a recognition that experience plays a greater role than formal training programmes in helping individuals to developing leadership skills (Yukl, 2013). The developmental value of experience is recognised across a range of empirical studies 
and different theoretical perspectives on learning and development (DeRue and Wellman, 2009; Waller et al., 2017).

In their review of research into leadership development, Day et al. (2014, p. 80) note: '...it is highly unlikely that anyone would be able to develop fully as a leader merely through participation in a series of programs, workshops, or seminars. The actual development takes place in the so-called white space between such leader development events.'

Informal learning activities, in contrast to the formal learning activities of training programmes, include networking, mentoring, action learning (Vito, 2018) talking and sharing resources with others, unstructured on-the-job training, collaborations, job rotation and observing others (Park and Jacobs, 2011) feedback-seeking and reflection (Sparr et al., 2017).

Research by Lombardo and Eichinger (1989) and McCall et al. (1988) has focused on the value of challenging experiences for leader development. This focus is justified by DeRue and Wellman (2009, p. 860): ' ...challenging experiences provide a platform for individuals to try new behaviors or reframe old ways of thinking and acting'. Mumford et al. (2000, p. 90) argue that '....assignments that present novel challenging problems and require working with others who have different perspectives may be valuable.' Bennis and Thomas (2002) indicate that the process of facing up to adversity can develop strength and commitment in leaders, while Yukl (2013) argues that some experience of failure may be necessary in order to enhance development.

Lombardo and Eichinger (1989) and McCauley et al. (1994) identify a range of 'developmental challenges' for executives, which include: taking on new responsibilities, managing projects that entail the possibility of success or failure, developing new directions, leading on projects with characteristics including significant outcomes, high visibility, job overload, intellectual challenges, the lack of key resources (such as direct authority, or top management support), and the need to work with new, diverse or difficult relationships.

Drawing on this, DeRue and Wellman (2009) identify five task-related characteristics that make work experiences developmentally challenging: unfamiliar responsibilities, high levels of responsibility, responsibility for creating change, a role that involves working across boundaries, and the need to manage diversity.

However, there is a recognition that more challenging experiences do not necessarily equate with more development. Just as stress may improve a person's performance up to a certain point, beyond which performance deteriorates, so a certain level of challenge may be of optimum developmental value (DeRue and Wellman, 2009), and greater levels may be destructive. Individuals are also more likely to benefit from challenging experiences if they have a positive attitude to learning (Heslin and Keating, 2017; McCall et al., 1988) and have some support (Yukl, 2013).

Experiential learning opportunities may be part of a formally-planned programme; Gold et al. (2010) list a range of activities, including enrolling the manager on special projects, committees or task groups, and providing coaching and mentoring. Much of 
the literature on experiential learning and management is concerned with the design of development programmes (e.g. Bevan and Kipka, 2012; Gitsham, 2012). A strong literature on coaching and mentoring indicates that these activities may be particularly valuable supports for leaders and managers to learn from the challenges of their jobs (Clutterbuck, 2014; Garvey et al., 2014). Feedback from others is also a process likely to be supportive of learning (Vito, 2018; Day et al., 2014) and reflection on experience by the learner is evidently valuable (Bennis, 2003; Byrne et al., 2018; Hezlett, 2010; Lundgren et al., 2017; McCall, 2010). Indeed, Ligon and Hunter (2010) argue that the important factor for development is the meaning that individuals garner from events, rather than the events themselves.

To summarise, there is substantial agreement that leadership development can be facilitated by the experience of activities in the workplace. Although there is no clear agreement on exactly what activities will be of value, there is some agreement that activities involving a degree of challenge are likely to be important, together with some factors providing a degree of support to enable the individual to beneficially learn from the more difficult experiences. However, there appears to have been little in the way of primary research in recent years into practices and experiences that may give rise to the development of leadership capabilities.

\section{Methodology}

Based on a review of literature, a survey was constructed listing a number of experiences that might be important for developing individuals as leaders, including activities such as taking on a new job, handing significant challenges, having a coach or mentor, seeing role models, and supervising staff. Sixteen items were included in the final survey. Respondents were also able to answer 'Other' and provide information on an experience that was not listed. Respondents were asked to rate the extent to which they thought that each of these had impacted on their development as a leader in the previous five years, on a scale of 1-5, where 5 indicated 'A great deal' and 1 indicated 'Not at all'; they could alternatively indicate that factors did not apply to them (e.g. that they had not experienced taking on a new job, or had not been coached or mentored). As well as rating each type of experience, respondents were also asked to indicate which item was the most important in developing their leadership capabilities, and to explain why.

In keeping with the idea from literature that hardships can provide valuable development experiences, a separate question listed five types of challenging experiences, and asked respondents to rate the impact of these. en a scale of $0-3$, where 0 indicated 'Not at all' and 3 indicated 'A great deal':

- Experiencing failures and mistakes

- Being turned down for contracts, promotions or other opportunities

- Handling staff performance problems

- Having difficult relationships with colleagues, boss or others

- Losing out in tough negotiations with colleagues, boss or others

In addition, participants were asked about factors that facilitated learning from experience, including time for personal reflection, and support from a variety of other people (line manager, colleagues, friends and family). An open question asked respondents what capabilities they believed they had developed, and a final question 
asked if respondents would be willing to provide more information, through interview or an exchange of emails.

The survey was piloted with a group of mature managers and professionals attending a management development programme, and adjustments were subsequently made to some of the items. Graduates of an international executive Master's programme were invited to undertake the survey; 190 replies were received, and further information was gathered by an exchange of emails with 25 respondents.

The project received research ethics approval from the university to which the authors are attached.

\section{Findings}

The majority of respondents (78\%) were 45 years of age or older; $67 \%$ were employed in the private sector; $69 \%$ were male and $31 \%$ female. Asked about their position in their organisation, $25 \%$ described themselves as an owner/principal; $11 \%$ described themselves as a chief executive; $37 \%$ said they were a senior manager other than a chief executive, and $17 \%$ said they were a middle manager.

The majority of respondents $(71 \%)$ said they thought they had developed their leadership capabilities 'a great deal' in the previous five years, with a further $25 \%$ saying they thought they had developed these capabilities 'moderately', and 4\% saying they thought they had developed only 'a little'.

This section of the paper summarises the quantitative and qualitative responses to the survey on the respondents' perceptions of experiences that aided the development of leadership capabilities, the types of hardship that had an impact on development, and the factors that provided support for learning.

\section{Experiences aiding development}

The experience that was scored most highly in developing leadership capabilities was 'Tackling a significant challenge or challenges', followed by 'Taking, or contributing to, major decisions'. Scores for all the listed activities are set out in Table 1. The raw average scores indicate the average across all respondents, where 5 means 'a great deal', 1 equals 'not at all' and 0 equals 'I did not experience this'; the adjusted average scores are calculated after those respondents who did not experience the activity have been omitted.

The raw averages indicate how important each activity was across all respondents, whilst the adjusted average indicates how important the activity was to those people who experienced it: for example, over $15 \%$ of respondents said they had not taken on a new job in the previous five years; over $22 \%$ of respondents said they had not experienced having a mentor/coach in that time; almost $11 \%$ of respondents said they had not been given formal feedback, so there is quite a large difference between the raw and adjusted average in these cases.

There were no significant differences between the responses of males and females. With regard to age, while younger respondents (44 years or less) scored many of the 
experiences slightly higher than older respondents (55 years or more), the differences were not statistically significant.

\section{TABLE 1 HERE}

Apart from two items, there were no significant differences between the responses from individuals in different roles in their organisations. One exception was the item 'Learning from other people I met through work, such as clients, competitors, people from other organisations'. Almost $40 \%$ of all respondents said that this had impacted 'a great deal' on their development, but chief executives and owners/principals were more likely to credit it with having a major effect on their learning than those respondents in other roles $(p<0.02)$. The other exception was 'Getting informal feedback', where chief executives rated this more highly than those in other roles ( $p$ $<0.02)$.

Qualitative data from open questions and follow-up email exchanges provided more information on the categories in the survey. The most popular category - Tackling a significant challenge or challenges - was broader than the more specific developmental activities described by Lombardo and Eichinger (1989) and McCauley et al. (1994), and information was sought about the nature of the challenges experienced by respondents, and what this meant for them in terms of their development. The significant challenges nearly always appeared to entail tackling something new - a larger task, a more strategic role, a position with new responsibilities, or a task requiring the individual to work with different stakeholders. Some respondents talked of this stretching their capabilities, others of this bringing about changes in perspective. For example:

I have developed professionally through repeated exposure to complex operational and technical leadership challenges. The most significant of these have involved 'crisis management', in contexts where others have failed - or are failing - and I had volunteered to go in and come up with (and implement) the fix.

... what had the most impact on my professional development in the last five years was: 'Taking on new jobs with increasing levels of responsibility'. The new jobs represented (1) new challenges - facing them and successfully finding my way through the thin and the thick contributed to my professional development, (2) increased management responsibilities in terms of the size and complexity of interventions, as well as of the teams. I was (still am) faced with 'having to become more strategic and effective as a survival strategy' and searching for ways to be effective in supervising a larger number and broader diversity of persons, which requires to adapt my leadership style, and (3) having more influence on the organisational culture.

Moving into a role with broader responsibilities and "stepping up" to the demands of that role based on the basic capabilities I already had. Once you do that - it becomes real, you have to adjust your perspective - become broader, less emotional, think through 360 degree of perspectives. 
The new jobs [meant] I was (still am) faced with having to become more strategic and effective as a survival strategy and searching for ways to be effective in supervising a larger number and broader diversity of persons, which requires [me] to adapt my leadership style

Tackling a significant challenge or challenges... developed my capacity for leadership because it challenged my limits, self-confidence and the need to create consensus with those that I led.

Taking on new responsibilities has contributed to my development in... [helping me learn how to] not be afraid of things I don't know, and willing to take on challenges that might not necessarily work out, enforced my leadership position as a positive, optimistic leader...

Taking on new responsibilities, including taking on a new job, was rated highly developmental for many of the respondents who had experienced this. Respondents talked of learning new skills and knowledge, coping with additional responsibility, and interacting with new and different people:

Taking on new jobs or new tasks as part of existing roles. Requires selfanalysis in the process of getting a new role, plus the opportunity to view an organisation with fresh eyes, effectively stepping out of existing alliances and concepts.

...taking on a new job [...] entailed managing the office of a very senior member of staff and that set me up to 1) gain confidence that I could do the job; 2) added responsibility meant increased accountability; 3) my leadership skills in the area of communication improved amazingly; 4) were I to consider team dysfunctions, I have grown in the area of trust-building as a leader, based on my position and expectations of the job; 5) managing resources, especially time, is another area I have improved on; 6) cultural adaptability and sensitivity is another area that has been vastly improved by exposure in this new position.

Taking a new job. Looking at things differently and behaving like a beginner and willing to learn and make a valuable impact though action rather than words or title

Many of the respondents acted internationally, and several responses concerned learning how to work within a different culture. For example:

Taking on a new job in a different culture made me realise that I had to examine and adjust my leadership style in order to achieve the desired results within the new culture.

Taking a new job in a different country. There was sharp contrasting differences in culture and work ethics between my country and the country I went to and had to adjust/change approach of working with colleagues and supervising staff. 
Taking on temporary new responsibilities (such as by being part of a project team) was rated less highly on the whole than taking on taking on a new job, or new responsibilities as part of one's existing job, but $29 \%$ of respondents said that this had impacted 'a great deal' on their development. However, by its aggregate score it was ranked only $9^{\text {th }}$ out of the 16 types of developmental activities included in the survey.

Formal feedback, such as through an appraisal system was rated relatively low impact, with only $21 \%$ of respondents believing that it had affected their development a great deal. Informal feedback was rated more highly. One respondent said:

Getting informal feedback [has helped me] because during the exchange that takes place in the team informal feedback is the most brutally honest reflection of the impact one has on others [working] towards a common goal. This has assisted me to make necessary adjustments and grow my influence.

Being mentored/coached was also scored relatively low by respondents: $20 \%$ said that it had helped their development a great deal, but $11 \%$ of those who had experienced it said that it had not helped their development at all. Acting as a mentor/coach for others was rated more highly, with $40 \%$ of respondents who had experienced this saying it had helped their development a great deal, and only $3 \%$ saying it had not aided their development at all. One said:

Acting as mentor/coach to someone else [was the most important thing for me]. Being responsible and accountable for a very immature (newly promoted) junior leadership team that has needed significant guidance on many aspects of leadership, particularly in the area of people skills.

The relatively low scores for these experiences most likely to be shaped by human resources departments - feedback from appraisals, being mentored/coached, temporary assignments - contrasts with the perceptions of greater development potential inherent in tackling new challenges, contributing to major decisions, and taking on new and weighty responsibilities.

\section{Hardships}

Respondents were asked about five specific types of hardships, and invited to rate the impact each hardship had on their development, from 3 - 'a great deal' - to 0 'not at all'. Responses are as shown in Table 2.

In this section of the survey, $44 \%$ of respondents said that experiencing failures and mistakes had impacted 'a great deal' on their development, while only $3.5 \%$ said it had affected them 'not at all'. A number of respondents added that an unstable environment had created challenges. For example:

Political instability in the last five years in particular - both in the country, and also within the institution, (with multiple complete changes of senior administrators in the last three years) has set some challenges in continuing to be a leader and manager - learning to manage my own feelings and help 
others with theirs, especially in times of terrorist acts here and the reaction [of] those who create and enforce the law.

\section{TABLE 2 HERE}

Difficult relationships with others was scored highly by $35 \%$ of respondents. One talked of working for 'an intractable boss', another of opposition when she took charge of an organisational change initiative:

During the change initiative some of my colleagues experienced a dismantling of their power base which resulted in a lot of their angst and aggression being directed towards me. I had to learn quickly not to take it personally and to keep the program on course, dodging the many bullets that came my way [...] Support from the Head of the Organization helped a great deal.

There were no significant differences between the scores awarded by different groups of respondents.

\section{What helped with the learning process}

Respondents were asked to indicate the extent to which a number of factors were important in helping with the learning process, on a scale of 1-5, where 5 was 'Very important' and 1 was 'Not important at all'.

\section{TABLE 3 HERE}

As shown in Table 3, time for personal reflection was scored highest, with $75 \%$ of respondents judging it to be 'Very important'. Support from family/friends was the next most highly scored item, with $38 \%$ of respondents judging it to be 'Very important'. The actions of line managers in providing support or advice/feedback were the lowest rated items. There were no significant differences between the scores awarded by different groups of respondents.

Two activities that had helped leaders learn from their experiences were identified in qualitative responses as listening to, and understanding, others with different viewpoints, and taking a more strategic perspective on issues: achieving a better understanding of the 'bigger picture' or the 'longer game'. One respondent referred to both these activities, when they said they had learned to 'be strategic and address multiple perspectives'.

\section{Discussion}

Literature on the development of leadership capabilities has noted the importance of workplace experience in provoking and supporting individuals to develop their skills (Day et al., 2014; Gold et al., 2010; McCall, 2004). DeRue and Wellman (2009) have argued that challenging experiences require managers to try new behaviours, and to reframe old ways of thinking and acting. This research confirms and extends this understanding of the role of experience in leadership development. 
Respondents to the survey perceived challenging experiences as the phenomena that were of most importance in developing their leadership capabilities, closely followed by taking or contributing to major decisions, and taking on new responsibilities. Characteristics of these types of experiences were that they presented individuals with new and difficult situations. Many respondents noted the need to develop new skills, and also a growth in self-confidence. DeRue and Wellman (2009) write of leaders learning through 'reframing' old ways of thinking: the respondents in this research talked of learning to understand new situations and new stakeholders, developing different perspectives, 'looking at things differently' and viewing the organisation 'with fresh eyes'. Mumford et al. (2000) have noted the value of working with others who have different perspectives: a number of respondents talked of the need to achieve consensus with different groups, and to engage in collaborative working.

There is a tendency for writers and researchers in this area (e.g. Gold et al., 2010; Lombardo and Eichinger, 1989; McCall, 2010; McCauley et al., 1994) to consider certain workplace experiences as events that may be designed (by organisations and/or their HR functions) in order to enable individuals to develop leadership capabilities. An alternative view is that individuals will develop their capabilities through these experiences, whether they are designed for developmental purposes or whether they arise for other reasons. The relatively low scores awarded in the survey to controlled interventions such as coaching/mentoring, appraisal feedback and temporary new responsibilities indicate a perception that these are of relatively limited impact in developing leadership capabilities. The relatively low scores given to the support, advice and feedback provided by line managers also indicate a perception that this source is of limited value in supporting learning and development. Advice and feedback from colleagues was rated more highly, but not as highly as time for reflection, or support from family/friends.

Some of the experiences identified by the respondents in this research are disruptive, difficult to manage, and no doubt stressful. A practical question for those who are involved in developing managers and leaders is how best to prepare people for these experiences, and how best to support them through the times of challenge, and enable them to learn and develop their leadership capabilities.

Other experiences judged to be valuable in developing leadership capabilities are less disruptive - such as learning from other people outside the organisation, coaching/mentoring others, and training others: in these cases individuals are likely to realise most value from the opportunity if they are made aware of the potential of these experiences for developing their capabilities. The importance of making time for reflection in order to learn from experience was rated very highly by respondents in this research. Learning activities respondents said had helped them to reframe their understanding included active listening to understand different viewpoints, and more strategic thinking to see situations in new perspectives.

\section{Conclusion}

This research identifies a number of experiences - other than undertaking training and development programmes - that mature managers and professionals regard as important for their development as leaders. These are recent events, experienced within the last five years. Mature respondents to the survey said that they believed 
they had developed their capabilities as leaders in the previous five years, and indicated the kinds of experiences that had helped them to do so. The experiences that were most highly rated involved facing challenges, contributing to major decisions, and taking on new responsibilities. However, other experiences that were judged to have a positive impact on development included learning from others such as clients, competitors and people from other organisations - and acting as a coach/mentor to others.

The research was carried out with mature graduates of an executive master's degree programme, and these individuals may be more attuned to learning and development than others in similar positions of management and leadership. However, if these findings do apply more widely, those who are involved in leadership development should consider how best to raise awareness of managers and professionals of the opportunities posed by these workplace experiences, and what learning strategies and supports may be of most benefit. and how best to provide helpful and timely support where appropriate. 


\section{References}

Amit, K., Popper, M., Gal, R., Mamane-Levy, T. and Lisak, A. (2009),"Leadershipshaping experiences: a comparative study of leaders and non-leaders", Leadership \& Organization Development Journal, Vol. 30 No. 4, pp. 302 - 318.

Bennis, W. (2003), On Becoming a Leader, Perseus, New York City, NY.

Bennis, W. and Thomas, R.J. (2002), "Crucibles of leadership", Harvard Business Review, September, pp. 39-45.

Bevan, D. and Kipka, C. (2012),"Experiential learning and management education", Journal of Management Development, Vol. 31 No. 3, pp. 193 - 197.

Byrne, A., Crossan, M. and Seijts, G. (2018), "The development of leader character through crucible moments", Journal of Management Education, Vol. 42 No. 2, pp. 265-293.

Clutterbuck, D. (2014). Everyone Needs a Mentor, CIPD, London, England.

Day, D.V. and Thornton, A. (2018), "Leadership development", in Antonakis, J. and Day, D.V. (Eds.), The Nature of Leadership, Sage, London, England, pp. 354-380.

Day, D.V., Fleenor, J.W., Atwater, L.E., Sturm, R.E. and McKee, R.A. (2014), "Advances in leader and leadership development: A review of 25 years of research and theory", The Leadership Quarterly, Vol. 25, pp. 63-82.

DeRue, D.S. and Wellman, N. (2009), "Developing leaders via experience: The role of developmental challenge, learning orientation, and feedback availability", Journal of Applied Psychology, Vol. 94 No. 4, pp. 859-875.

Garvey, B., Stokes, P. and Megginson, D. (2014), Coaching and Mentoring theory and practice, Sage, London, England.

Gitsham, M. (2012), "Experiential learning for leadership and sustainability at IBM and HSBC", Journal of Management Development, Vol. 31 No. 3, pp.298-307.

Gold, J., Thorpe, R. and Mumford, A. (2010), Leadership and Management Development, CIPD, London, England.

Heslin, P.A. and Keating, L.A. (2017), "In learning mode? The role of mindsets in derailing and enabling experiential leadership development", The Leadership Quarterly, Vol. 28, pp. 367-384.

Hezlett, S.A. (2010), "Suggestions for new research on experience-based learning", Industrial and Organizational Psychology, Vol 3, pp. 56-60.

Ligon, G.S. and Hunter, S.T. (2010), "Putting the development into experiential development”, Industrial and Organizational Psychology, Vol. 3, 28-32.

Lombardo, M. and Eichinger, R.W. (1989), Eighty-eight assignments for development in place, Center for Creative Leadership, Greensboro, NC. 
Lundgren, H., Bang, A., Justice, S.B., Marsick, V.J., Poell, R.F., Yorks, L., Clark, M. and Sung, S.Y. (2017), "Conceptualizing reflection in experience-based workplace learning", Human Resource Development International, Vol. 20 No. 4, pp. 305-326.

McCall Jr., M.W. (2004), "Leadership development through experience", Academy o/ Management Executive, Vol. 18 No. 3, pp. 127-130.

McCall Jr., M.W. (2010), "Recasting leadership development", Industrial and Organizational Psychology, Vol. 3, pp. 3-19.

McCall Jr., M.W., Lombardo, M.M. and Morrison, A.M. (1988). The lessons of experience, Lexington, New York.

McCauley, C.D., Ruderman, M.N., Ohlott, P.J. and Morrow, J.E. (1994), “Assessing the developmental components of managerial jobs", Journal of Applied Psychology, Vol. 94 No.4, pp. 544-560.

Mumford, M.D., Marks, M.A., Connelly, M.S., Zaccaro, S.J. and Reiter-Palmon, R. (2000), "Development of leadership skills: experience and timing", The Leadership Quarterly, Vol. 11, No. 1, pp. 87-114.

Park, Y., and Jacobs, R. L. (2011) "The influence of investment in workplace learning on learning outcomes and organizational performance", Human Resource Development Quarterly, Vol. 22 no. 4, pp. 437-458.

Sparr, J.L., Knipfer, K and Willems, F. (2017), "How leaders can get the most out of formal training: the significance of feedback-seeking and reflection as informal learning behaviors", Human Resource Development Quarterly, Vol. 28 No. 1, pp. 2954.

Vito, R. (2018), "Leadership development in human services: Variations in agency training, organizational investment, participant satisfaction, and succession planning", Human Service Organizations: Management, Leadership \& Governance, Vol. 42 No. 3, pp. 251-266.

Waller, L., Reitz, M., Poole, E., Riddell, P.M. and Muir, A. (2017) "Experiential learning as preparation for leadership: An exploration of the cognitive and physiological processes", Leadership \& Organization Development Journal, Vol. 38 No. 4, pp.513-529.

Yukl, G. (2013), Leadership in Organizations, Pearson, Upper Saddle River, NJ. 